\title{
O DEVIR DAS SOMBRAS: \\ A LÓGICA POÉTICA EM “EL MONO GRAMÁTICO”
}

Olga Valeska*

RESUMO:

\begin{abstract}
Octavio Paz, em seu poema em prosa "El mono gramático", desenha uma cosmologia com os mesmos liames com que elabora poemas. A partir de uma lógica poética, ele constitui, assim, um cosmos regido por um tempo, paradoxalmente, múltiplo e pontual, escandido pela intensidade: um espaço em branco, ilimitado; ou um labirinto onde todas as linhas se encontram $e$ os passos do caminhante mudam a configuração dos próprios caminhos.
\end{abstract}

PALAVRAS-CHAVE: poética, Octavio Paz, cosmologia.

No poema em prosa, El Mono Gramático, escrito pelo poeta Octavio Paz, o personagem Hanumân, deus-macaco da mitologia védica, dá nome aos objetos do mundo: abre caminho por entre a natureza caótica e infinita criada pelos deuses. Esse gesto pode ser pensado como uma primeira vitória da "gramática" contra o "caos" insondável da natureza, uma primeira compreensão. Porém, como acontece no texto bíblico, um espaço simplesmente nomeado, "gramática ontológica", não perde sua dimensão paradisíaca, ainda que se apresente como que penetrado pela linguagem: "El paraíso esta regido por una gramática ontológica: las cosas y los seres son sus nombres y cada nombre es própio." (Paz, 1974: 96)

Os nomes, nesse contexto, não perdem a força encantatória da palavra eficaz: não produzem ainda significação, são como nomes próprios, unívocos. No texto paziano, Hanumân é um ser híbrido, um misto de deus, de animal e, pelo uso da palavra, é também semelhante ao homem. Assim, na verdade, sua linguagem não é

| Doutora em Letras: Estudos Literários (Ārea de concentração: Literatura Comparada), 2003. 


\section{EMTESE}

Belo Horizonte, v. 8, p. I-243, dez. 2004

propriamente humana. Ela se aproxima, em parte, da linguagem divina, prenhe de força numinosa. Porém, diferente do que acontece no contexto bíblico, as suas palavras não podem ser associadas a um gesto Criador, mas representam uma metamorfose ou uma tradução. E essa metamorfose busca salvar a natureza de sua estranheza irredutível que se abre, como um enigma, diante do olhar de Hanumân:

(...) la vegetación asume una apariencia irreal, casi incorpórea, como si fuese una mera configuración de sombras y luces sobre un muro. Pero es impenetrable. (...) delicia de los ojos, derrota del entendimiento. (p. 43)

No entanto, o mundo de nomes próprios que surge a partir de seu gesto constitui um tecido também impenetrável, outra caligrafia emaranhada, quase tão insondável quanto a natureza. As palavras, como o mundo das coisas, também são como sombras e luzes projetadas no muro, são também ininteligíveis, e Hanumân parece fugir da presença insólita desse mundo e da inconsistência de seu próprio gesto:

El Gran Mono cierra los ojos, vuelve a rascarse y musita: antes de que el sol se hubiese ocultado del todo - ahora corre entre los altos bambúes como un animal perseguido por la sombra - logré reducir el boscaje a un catálogo. (Paz, 1974: 46)

Assim, ao nomear o mundo, Hanumân passa a fugir das sombras que ele próprio produziu. Ele passa a habitar um mundo também fugidio onde as presenças/ nomes se abrem na densidade vegetal das próprias formas do mundo: "Una página de enmarañada caligrafía vegetal. (...)" (Paz, 1974: 46). Porém, o questionamento da palavra divina surge, não do momento de reconhecimento ingênuo do mundo, mas do desejo de conformá-10 a uma lógica racional. 0 homem, neste momento, empreende a tarefa demoníaca de "decifrar" o mundo, moldando-o à sua imagem e semelhança. É esse o seu exílio radical do espaço sagrado: ser prisioneiro de sua própria liberdade:

Caminar: leer el trozo de terreno, descifrar un pedazo de mundo. La lectura considerada como un camino hacia (...) La crítica del universo (y la de los dioses) se 11 ama gramática... Turbado por este extraño pensamiento, Hanumân salta de la barda al suelo, (...) escruta los cuatro puntos cardinales y, con decisión, penetra en la maleza. (Paz, 1974: 47)

Dessa forma, no momento em que Hanumân cria uma gramática capaz de questionar a lógica divina, pode ser identificado com o próprio homem. A escrita dos homens seria, assim, uma segunda tradução, não mais do próprio mundo, mas do texto arcaico que o nomeou; uma conformação dessa massa informe de palavras à lógica 
humana. A escrita do homem não pretende apenas nomear, mas significar: é, na verdade, uma "leitura", um caminho trilhado na densidade obscura do mundo: "Una página de enmarañada caligrafía vegetal. Maleza de signos: ¿Cómo leerla, cómo abrirse paso entre esta espesura?" (Paz, 1974: 46-7).

Com esse gesto, Hanumân cai, como o homem, prisioneiro da "maleza" da linguagem que se constitui de "nombres huecos", "hinchados de su própia realidad", plenos de um sentido estranho a eles mesmos. 0 homem está condenado a usar uma palavra em estado de queda: crítica à ilegibilidade da escrita divina que ocasionou a separação radical entre o homem e o espaço sagrado. E o vazio, a "falta" original da condição de "ser" (separado) não é percebida senão pela dor da cicatriz original (a dor de existir) da qual ele nada pode dizer, porque essa "falta" está além da linguagem, e é a linguagem mesma que tornou possível a metáfora original que configura o homem como "ser de linguagem": um exilado de si mesmo. Como afirma Octavio Paz:

El lenguaje es la consecuencia (o la causa) del nuestro destierro del universo, significa la distancia entre las cosas y nosotros. También es nuestro recurso contra la distancia. (Paz, 1974:114)

Assim, narrando o seu percurso pelo caminho de Galta, povoado em ruínas nas imediações de Jaipur, Octavio Paz configura, em filigrana, a Gênesis da palavra e a transgressão que levou o homem a seu estado de queda. No entanto, também representa uma proposta poética fundamentada numa escrita que se localizaria no viés mesmo entre o exílio humano e o seu desejo de reconciliação. Nesse aspecto, se o homem é separado da natureza pela linguagem, é somente através da linguagem que ele poderia ser capaz de vislumbrar um espaço mais além da palavra: um espaço de convergência entre a experiência sensível e a própria palavra articulada, não por uma lógica racional, mas por uma lógica poética, analógica. Nesse aspecto, a poesia pode ser pensada como o próprio corpo da personagem feminina, Esplendor: um corpo onde se encena todo o drama paradoxal da própria analogia, que gira em torno dos eixos instáveis da unidade e da multiplicidade; do ser e do devir do mundo: "Esplendor es esta página, aquello que separa (libera) y entreteje (reconcilia) las diferentes partes que la componen (...)" (Paz, 1974: 140).

Em El Mono Gramático, Esplendor nasce do suor que aflorou de Prajâpati, o Senhor das criaturas, um suor que flui do esforço de criar todos os seres: 


\section{EMTESE}

Belo Horizonte, v. 8, p. I-243, dez. 2004

"Mientras creaba a los seres, Prajâpati sudaba, se sofocaba y de su gran calor y fadiga, de su sudor, brotó Esplendor." (Paz, 1974: 81). Nesse instante, ela surge como uma unidade que cintila em meio à proliferação dos seres. Ela representaria, assim, um momento de convergência entre a liberdade e a reconciliação, o paradoxo que atravessa a existência, una e múltipla, do cosmos: "Reconciliación es identidad en la concordancia, liberación es identidad en la diferencia. Unidad plural, unidad unimismada. Otramente: mi smamente." (Paz, 1974: 84)

Observa-se que Esplendor, quando tem seu corpo repartido entre os deuses, para recuperar a sua unidade original, oferece aos deuses um sacrifício invertido: uma prece recitada ao revés. Essa passagem assinala um momento em que a palavra pode abalar a lógica linear da própria linguagem, gerando um paradoxo semelhante ao que marca, segundo 0 . Paz, o texto poético: texto que se inclina sobre si mesmo, na tarefa infinita que busca dissolver os "nomes", no instante mesmo de pronunciá-10s: "El poeta no es 10 que nombra las cosas, sino el que disuelve sus nombres, el que descubre que las cosas no tienen nombre y que los nombres con que las 11 amamos no son suyos." (Paz, 1974: 96)

Assim, a distância irredutível entre o objeto da experiência sensível e a linguagem constitui um espaço vazio de onde surge a demanda da escrita poética. E esse mesmo vazio torna o gesto de escrever como o próprio caminho de Galta descrito no poema: caminho que se recusa a fixar os passos do caminhante? escrita que se recusa a cristalizar-se em uma narrativa linear. 0 caminho, a partir dessa lógica poética, constituiria, assim, um "agora" que é sempre trânsito, e onde o "ser" é sempre "devir".

A medida que escribía, el camino de Galta se borraba o yo me desviaba y perdía en sus vericuetos. Una y otra vez tenía que volver al punto del comienzo. En lugar de avanzar, el texto giraba sobre sí mismo. ¿La destrucción es creación? No lo sé, pero sé que la creación no es destrucción. (Paz, 1974: 136)

Ressalte-se que a questão da impermanência, não é tomada no texto apenas como um tema de reflexão. Esse elemento, na verdade, constitui-se como articulador do discurso paziano e, como tal, é imanente ao próprio texto, presentificando, através da própria linguagem, a "dúvida" diante de qualquer conceito, de qualquer metáfora. Na narrativa, o ato de desfazer o tecido verbal (através da própria 
linguagem) é, paradoxalmente, sempre um acréscimo: o questionamento da metáfora se faz com outras metáforas que são interpoladas e que proliferam no texto. Assim, a indagação sobre o sentido da linguagem (e do mundo) se dá sempre através de outra indagação:

Destejer el tejido verbal: la realidad aparecerá. (Dos metáforas.) iLa realidad será el reverso del tejido, el reverso de la metáfora - aquello que está del otro lado del lenguaje? (El lenguaje no tiene reverso ni cara ni lados.) Quizá la realidad también es una metáfora (¿de qué y/o de quién?). (Paz, 1974: 26)

Dessa forma, pode-se dizer que esse tecido verbal não tem dimensão concreta, mas seria "não-inteira": uma dimensão fragmentada que atravessa as escalas, configurando uma espessura infinita. Por esse mesmo motivo, o gesto de apagar os nomes, paradoxalmente, torna-se possível, porque a linguagem deixa de ter limites: perde a forma capaz de impor fronteiras rígidas ao mundo. Assim, o narrador/poeta repete o gesto prometéico de Hanumân: criando "ramagens" de palavras, ele questiona tanto o mundo quanto a lógica e a razão da própria linguagem:

la realidad más allá de los nombres no es habitable y la realidad de los nombres es un perpetuo desmoronamiento, no hay nada sólido en el universo, en todo el universo, en todo el diccionario no hay una sola palabra sobre que reclinar la cabeza (...) (Paz, 1974: 54).

Pode-se dizer, assim, que a lógica poética, para 0ctavio Paz, instalase no limiar entre o habitável e o inabitável, entre o cosmos e o caos: as mesmas linhas que tecem as palavras são as mesmas que as destecem, configurando um intrincado tecido que não pode ter fim ou limite: sempre haverá uma distância a transpor, sempre haverá uma metáfora:

No hay principio, no hay palabra original, cada una es una metáfora de otra palabra que es una metáfora de otra y así sucesivamente. Todas son traducciones de traducciones. Transparencias en la que el haz es el envés: la fijeza siempre es momentánea. (Paz, 1974: 28)

Ora, para Octavio Paz, a linguagem é um lugar que é de todos e não é de ninguém: um lugar de convergência entre o "si-mesmo" e o "outro", um espaço de "otredad". Dessa forma, a linguagem configura um desenho móvel que, ao acolher a memória do sujeito poético, deforma-a e a decompõe: uma sombra projetando sombras, contaminando o texto com seus próprios traços. 0 poeta, nesse contexto, empreende 


\section{EMTESE}

Belo Horizonte, v. 8, p. I-243, dez. 2004

a tarefa infinita de remodelar, sempre, um devir de sombras projetadas no muro, sem poder (ou querer) evitar o travo irônico de lidar com o caos como parte constitutiva da própria lógica poética.

Em muitas passagens, o narrador descreve manchas de umidade que alteram o desenho dos afrescos nos muros de Galta:

En el muro de la terraza las proezas de Hanumân en Lanka se resuelven en una borrasca de trazos que se confunden con las manchas violáceas de la humedad. Unos pocos metros más adelante el lienzo de la pared termina en un montón de escombros. Por la gran brecha puede verse la tierra de Galta (...) (Paz, 1974: 67).

E essas manchas, no texto, funcionam como uma metáfora do próprio fazer poético em Octavio Paz: elas não configuram textos originais, mas transformam as linhas das pinturas, ora destruindo, ora acrescentando formas, numa metamorfose infinita que conta com a cumplicidade do tempo e soma-se às trincas e à deterioração do próprio muro. Assim, a poesia se confunde com as edificações em ruína. E o desenho que se vislumbra incide na tensão instável de um tempo escandido pela intensidade: "La irrealidad de aquella arquitectura y la realidad de su ruina presente se resolvían en un tercer término brutalmente inmediato y alucinante" (Paz, 1974: 93).

E qual seria esse terceiro termo? 0 texto de $\mathrm{Paz}$ não responde ou responde com a perplexidade de seu próprio silêncio: o narrador faz o fluxo das palavras pararem repentinamente (sem ponto final), desembocando no vazio e obrigando o leitor a buscar por um ponto além do texto. 0 terceiro termo, mudo, só pode fazer ressonar o lugar movediço e vertiginoso do "agora" que desapareceria no instante mesmo que se configurasse como palavra. Instaura-se, assim, a magia do "efêmero" que afirma a sua presença sem ser sequer nomeada. E o texto se mancha também da instabilidade do tempo da leitura: "en el otro lado, allá donde unos ojos leen esto que escribo y, al leerlo, 10 disipa." (Paz, 1974: 56)

É interessante notar que a citação acima também está constituîda por um parágrafo cujos limites se estendem pelo espaço vazio da página em branco. As próprias palavras são como momentos fugazes que anunciam sua dissipação no tempo da leitura. Assim, o texto, como a palavra numinosa dos antigos mitos, diz algo que seu corpo mesmo presentifica. Porém, o que ele presentifica é sua própria impossibilidade 
de ser enquanto "permanência". E mais uma vez, surge, às margens do texto, a imagem do "efêmero" que se propõe sempre como enigma, sem precisar ser nomeado.

A partir dessas reflexões, pode-se dizer que a poesia, para Octavio Paz, está impregnada pela mobilidade de um jogo de luz e de sombras: manchas de escuridão e brilho que sempre interferem no desenho do cosmos. As manchas não constroem cosmos, não erigem idéias, não lutam contra o tempo nem contra sua própria insubstancialidade. Ao contrário, essas variações de luz constituem uma constatação viva do tempo pontual do agora e de suas metamorfoses. São a aceitação silenciosa desse movimento que desestabiliza as formas do mundo.

É significativo que o momento do crepúsculo é repetido varias vezes no texto: um retorno constante a um momento em que luz e sombra se interpenetram em um lusco-fusco que rasura as fronteiras dos objetos: "Alianza de las claridades y las sombras: pausa universal." (Paz, 1974: 117) Por outro lado o crepúsculo acentua a mobilidade do "agora". É um momento de passagem que deixa visível o trânsito entre o dia e a noite. 0 "agora" no instante fugaz do crepúsculo representa sempre um salto que deixa ver a fixidez na mobilidade e a mobilidade na fixidez. E a escrita de Paz se confunde com o próprio crepúsculo. Uma escrita que não define os contornos dos objetos no mundo, mas se confunde com a penumbra que oculta os nomes no ato mesmo de nomear. E mais ainda, (re)vela o silêncio que transborda às margens de todas as palavras possíveis. É uma linguagem paradoxal que se inscreve na medida que explicita sua própria impossibilidade. Assim, pode-se afirmar que a poesia, em "El mono gramático", diz o indizível sem dizê-10. Como afirma Paz: "Enamorado del silencio, el poeta no tiene más remedio que hablar." (Paz, 1999: Paz, 1974: 297)

Em Octavio Paz, esse espaço em branco, o silêncio escavado pela linguagem poética não representa uma irrisão de sentido. 0 silêncio pára exatamente no ponto de convergência onde o sentido pode irromper. Essa possibilidade petrifica o texto, marcando o ritmo de uma espera: um caminho a trilhar, um tempo de penumbra onde 0 ocaso pode se reverter em madrugada. Porém, como já foi dito, este texto também é um caminho em direção a um fim que está sempre mais além do próprio caminho, é um devir. E a sombra e a luz que se movem sobre a superfície do muro passam a ter um mesmo significado: "la fijeza es siempre momentánea", assinalando a dança imóvel que só pode ocupar o espaço impossível entre o "ser" e o "não-ser" de um mundo que 


\section{EM TESE}

Belo Horizonte, v. 8, p. I-243, dez. 2004

se fundamenta na lógica paradoxal da analogia: "en esto ver aquello". Pode-se dizer, então, que a escrita poética se constrói em um tempo regido pela intensidade de um instante de convergências. Um labirinto onde todas as linhas se encontram ou, talvez, como um espaço aberto, ilimitado:

La visión de la poesía es la de la convergencia de todos los puntos. Fin del camino. Es la visión de Hanumân al saltar (géiser) del valle al pico del monte 0 al precintarse (aerolito) desde el astro hasta el fondo del mar (...). (Paz, 1974: 134)

ABSTRACT :

Octavio Paz, in his poem in prose, "El mono gramático," designs a cosmology with the same connections with which he develops his poems. Starting from a poetic logic, he thus builds a cosmos governed by a time that is paradoxically multiple and punctual, scanned by intensity: a space in white, unlimited; or a labyrinth where all the lines meet.

KEY WORDS: poetics, Octavio Paz, cosmology.

REFERÊNCIAS BIBLIOGRÁFICAS

PAZ, Octavio. El mono gramático. Barcelona: Seix Barral, 1974.

PAZ, Octavio. Obras Completas (v.1). México: Fondo de la Cultura Económica, 1999.

SPALDING, Tassilo Orpheu. Dicionário de mitologias européias e orientais. São Paulo: Cultrix/Instituto Nacional do Livro/MEC, 1973. 